\title{
Claudication without risk factors: a case of popliteal entrapment syndrome
}

\author{
Saggah Tarek Shalabi, ${ }^{1}$ Nadia Hussain, ${ }^{1}$ Haadi Tarek Shalabi, ${ }^{2}$ M Krishna Lingam ${ }^{1}$
}

${ }^{1}$ Derby Hospitals NHS Trust, Derby, UK

${ }^{2}$ University of Nottingham, Nottingham, UK

\section{Correspondence to}

Dr Saggah Tarek Shalabi, s.shalabi@nhs.net

\section{CrossMark}

To cite: Shalabi ST, Hussain N, Shalabi HT, et al. BMJ Case Rep Published online: [please include Day Month Year] doi:10.1136/ bcr-2013-202199

\section{DESCRIPTION}

A 54-year-old man presented with claudication in his left calf with a walking distance of $200 \mathrm{~m}$. There was no history of hypertension, hyperlipidaemia, thrombophilia, smoking or any risk factors associated with atherosclerosis.

Doppler scan demonstrated occlusion from the distal superficial femoral artery (SFA) to the proximal popliteal artery. A lower limb MR angiography supported this and showed significant collateralisation (figure 1). He underwent CT angioplasty with immediate symptomatic relief.

The relief was temporary, as 2 months later he presented with a recurrence of symptoms. The case was atypical as there were no significant risk factors and while the lesion was attributed to embolus, no cardiac source could be found. Therefore, the possibility of popliteal artery entrapment syndrome (PAES) was considered.

A further CT scan in the neutral and plantar flexed positions was able to demonstrate a short tight stenosis in the popliteal artery which was lying abnormally; medial rather than lateral to the medial head of gastrocnemius (figure 2). This correlated with type 2 PAES. ${ }^{1}$

In theatre the patient was placed in the prone position, and an S-shaped incision was made exposing the popliteal fossa. The medial gastrocnemius



Figure 1 MR angiography demonstrating occlusion and significant collateralisation.

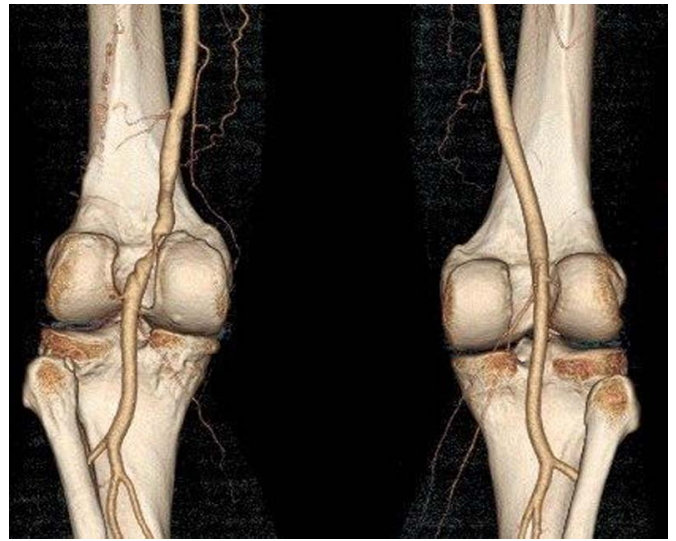

Figure 2 CT scan demonstrating stenosis of the popliteal artery.

ran from medial to lateral compressing the popliteal artery behind the knee in a sling fashion (figure 3). The sling was divided allowing the artery to lie free (figure 4). The SFA above the compression was hard to touch.



Figure 3 Popliteal artery compressed by abnormally lying medial gastrocnemius.

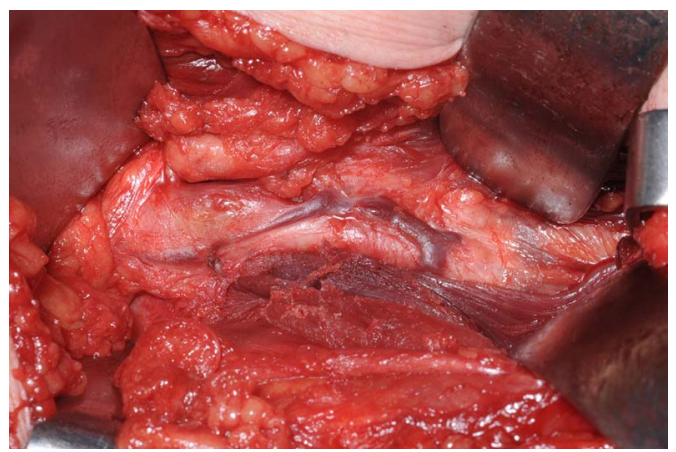

Figure 4 Popliteal artery now lying free (medial gastrocnemius released). 
Three months later the patient had CT angioplasty of his SFA with immediate relief and is now symptom free.

\section{Learning points}

- Vascular surgery atherosclerosis plays a major role in the underlying pathology in much of the field. However, anatomical abnormalities such as popliteal artery entrapment syndrome (PAES) must be considered, especially in younger patients with few or no risk factors.

- PAES usually occurs in patients in their early $30 s,{ }^{1}$ but as demonstrated in this case it can occur in older patients.

- CT angiography is useful in determining arterial changes and abnormalities in anatomical structures. ${ }^{2}$

- A follow-up protocol should be maintained for PAES which may increase efficiency of treatment and subsequent investigations for further treatment if deemed necessary.
Contributors The authors of this article were directly involved in this patient care and have all contributed to the writing of the article.

\section{Competing interests None.}

Patient consent Obtained.

Provenance and peer review Not commissioned; externally peer reviewed.

\section{REFERENCES}

1 Sinha S, Houghton J, Holt PJ, et al. Popliteal entrapment syndrome. J Vasc Surg 2012:55:252-62.

2 Macedo TA, Johnson CM, Hallett JW Jr, et al. Popliteal artery entrapment syndrome: role of imaging in the diagnosis. Am J Roentgenol 2003;181:1259-65.

Copyright 2013 BMJ Publishing Group. All rights reserved. For permission to reuse any of this content visit http://group.bmj.com/group/rights-licensing/permissions.

BMJ Case Report Fellows may re-use this article for personal use and teaching without any further permission.

Become a Fellow of BMJ Case Reports today and you can:

- Submit as many cases as you like

- Enjoy fast sympathetic peer review and rapid publication of accepted articles

- Access all the published articles

- Re-use any of the published material for personal use and teaching without further permission

For information on Institutional Fellowships contact consortiasales@bmjgroup.com

Visit casereports.bmj.com for more articles like this and to become a Fellow 